\title{
Quantification of Biofilm Formation in Indian Isolates of Salmonella enterica
}

\author{
Sophia Inbaraj ${ }^{1 *}$, Ravi Kant Agrawal ${ }^{2}$, R.K. Agarwal ${ }^{1}$, Prasad Thomas ${ }^{1}$, \\ Manish Kumar ${ }^{1}$, Abhishek ${ }^{1}$ and Pallab Choudhury ${ }^{1}$
}

${ }^{1}$ Division of Bacteriology and Mycology, ${ }^{2}$ Food Microbiology Lab, Livestock Products

Technology, ICAR-Indian Veterinary Research Institute, Izatnagar-243122, India

*Corresponding author

\section{A B S T R A C T}

\section{Keywords}

Biofilms,

Salmonella, Poultry,

Microtitre plates,

Farm animals

Article Info

Accepted:

18 January 2019

Available Online:

10 February 2019
A total of 60 Salmonella isolates (43 poultry origin, 17 farm animal origin) received from various parts of the country were used in the current study. The objective is to study the biofilm forming potential of the isolates using microtitre plate assay. Study revealed that $38 \%$ of the isolates were moderate biofilm producers and $37 \%$ were strong biofilm formers. As biofilm contribute to virulence and antimicrobial resistance of the organism, the study remains significant in food safety aspect.

\section{Introduction}

Non typhoidal Salmonella sps., is a gram negative bacterial pathogen associated with gastrointestinal tract of farm animals like cattle, pigs and poultry (WHO, 2013). The organism transmits to human via faeco-oral route and causes food borne illness. Non typhoidal salmonellosis outbreaks occur worldwide comprising about 93 million cases of gastroenteritis and 1,55, 000 deaths annually (Majowicz et al., 2010). Various virulence factors of Salmonella sps., which helps in adhesion and invasion are responsible for the pathogenicity. In addition, Salmonella sps., also possess the ability to form biofilms. Biofilms are the aggregates of bacterial species inside an extracellular polysaccharide matrix. Inside biofilms, bacteria will be in natural stationary phase (Lopez et al., 2010) and their physiology will be different from that of their planktonic counterparts. This helps the bacteria to escape from host immune response. It has been studied that Salmonella sps., could able to form biofilms in various surfaces such as plastic, stainless steel, glass, rubber, gall stones, animal cells and plants (Steenackers et al., 2012). The bacteria 
residing inside biofilms thus protect themselves from UV light, disinfectants, antimicrobial agents etc (Lianou and Koutsoumanis, 2012). Therefore biofilm indirectly contributes to the organisms' virulence and antimicrobial resistance. Various phenotypic methods like test tube method, microtitre plate test, congo red agar test (CRA) and colony count enumeration method have been widely used to study the biofilms. Apart from this, microscopic techniques like Confocal laser microscopy, Scanning Electron Microscopy, Optical coherence tomography and genotypic methods involving relative expression of biofilm associated genes in quantitative PCR have also been used to study biofilms (Merino et al., 2017). Among these, microtititre plate method was the simplest quantitative method to study the biofilms. In the current study, biofilm quantification using microtitre plate method has been done to 60 Salmonella enterica isolates.

\section{Materials and Methods}

\section{Bacteria}

60 Salmonella enterica isolates stored in buffered nutrient slant at National Salmonella Centre, IVRI, Bareilly were used in the current study. The cultures were revived in BHI broth and streaked on Hektoen Enteric plates. Among the 60 bacterial isolates, 43 were from poultry origin and 17 were from farm animals like sheep, goat, pig and cattle. The serovars used for the study includes Typhimurium, Kentucky, Virchow, Enteritidis, Welteverden, Heidelberg, Bovismorbificans, Rough Salmonella, Eastbourne, Dublin, Gallinarum, Haifa, Sandiego, Paratyphi B, Berto and Indiana.

\section{Biochemical test}

The isolates were confirmed biochemically by streaking them in Triple Sugar Iron agar
(Himedia, India). The TSI agar contains sugars such as $0.1 \%$ glucose, $1 \%$ sucrose and $1 \%$ lactose, ferric ammonium salts as hydrogen sulphide indicator and phenol red as $\mathrm{pH}$ indicator.

\section{Polymerase chain reaction for invA gene}

The PCR for invA gene was performed as per Galan et al., (1992) with certain modifications. The reaction mixture was optimized to contain $12.5 \mu \mathrm{L}$ of $2 \mathrm{X}$ PCR buffer, 10 pmol of each forward and reverse primers (Table 1) and $5 \mu \mathrm{l}$ of bacterial lysate prepared by boiling and snap chilling method and nuclease free water was added to make up the volume to $25 \mu \mathrm{l}$. The PCR cycling condition comprised of an initial denaturation at $94^{\circ} \mathrm{C}$ for $1 \mathrm{~min}$, primer annealing at $50^{\circ} \mathrm{C}$ for $1 \mathrm{~min}$, elongation at $72^{\circ} \mathrm{C}$ for $1 \mathrm{~min}$ and finally a single step extension at $72^{\circ} \mathrm{C}$ for 7 min. The PCR products were analysed by running in $1.5 \%$ agarose gel electrophoresis gel.

\section{Biofilm assay}

The quantification of biofilms was done in 96 well microtitre plates as per Stepanovic et al., (2004) with little modifications. Various serovars of Salmonella enterica were used in the current study. Briefly, $80 \mu \mathrm{L}$ of the overnight grown culture was mixed with 920 $\mu 1$ Luria Bertani (LB) broth and $250 \mu 1$ of the later in triplicate was pippeted in each well of the plate.

The plates were covered with aluminium foil and incubated at $37^{\circ} \mathrm{C}$ for $48 \mathrm{hrs}$. After 48 hrs, the contents were poured off and washed with $250 \mu \mathrm{l}$ of sterile distilled water. The biofilms are fixed with methanol @ $250 \mu \mathrm{L}$ /well for $15 \mathrm{~min}$. The contents were poured off and air dried. Staining is done with crystal violet @ $250 \mu \mathrm{L} /$ well for 5 min followed by washing with sterile distilled water. Resolubilization of the dye was done in $33 \%$ 
glacial acetic acid @ $250 \mu \mathrm{l} /$ well. The absorbance was measured at optical density of $570 \mathrm{~nm}$. Three wells containing LB broth without any culture is considered as control.

Classification of test isolates based on biofilm intensity

The isolates are classified into various categories based on the optical density (OD) of the control as per Stepanovic et al., (2004) as follows:

$\mathrm{OD}_{\text {control }}=3$ (Standard deviation) above the mean OD of negative control

1) ${\text { No biofilm producer }=\mathrm{OD}_{\text {test }} \leq \mathrm{OD} \text { control }}$

2) Weak biofilm producer $=\mathrm{OD}$ control $<\mathrm{OD}$ test $\leq\left(2 \times \mathrm{OD}_{\text {control }}\right)$

3) Moderate biofilm producer $=(2 \times \mathrm{OD}$ control $)<\mathrm{OD}_{\text {test }} \leq\left(4 \times \mathrm{OD}_{\text {control }}\right)$

Strong biofilm producer $=\left(4 \times \mathrm{OD}_{\text {control }}\right)<$ OD test

\section{Results and Discussion}

\section{Bacterial growth}

All the Salmonella enterica isolates produced transparent green or bluish green colonies with black centres.

\section{Biochemical test}

After 18-24 h of inoculation, the organisms produced alkaline slant and acid butt with black precipitate and gas production. The organism could able to ferment only glucose to $\mathrm{CO}_{2}$, with $\mathrm{H}_{2} \mathrm{~S}$ production.

\section{Molecular characterization}

PCR amplification of the isolates targeting invA gene revealed specific amplification at $284 \mathrm{bp}$ on agarose gel electrophoresis.

\section{Biofilm assay}

Among the 60 isolates, 9 isolates were observed as non biofilm producers, 6 isolates as weak biofilm producers, 23 as moderate biofilm producers and 22 as strong biofilm producers.

Among the 43 poultry isolates, majority are moderate biofilm producers (17) followed by strong biofilm producers (15). Among the 17 farm animal isolates, majority were strong biofilm producers (7) followed by moderate producers (6). The tabular form of the biofilm assay results were presented in Table 2 .

Table.1 Primer sequence

\begin{tabular}{|l|l|l|l|}
\hline S.No & Gene & Primer sequence & Product size \\
\hline $\mathbf{1}$ & $\begin{array}{l}\text { invA F } \\
\text { invA R }\end{array}$ & GTGAAATTATCGCCACGTTCGGGCAA & TCATCACCGTCAAAGGAACC \\
\hline & & & \\
\hline
\end{tabular}

Table.2 Biofilm assay

\begin{tabular}{|l|l|l|l|l|l|}
\hline Animal & Non biofilm & Weak & Moderate & Strong & Total \\
\hline Poultry & 6 & 5 & 17 & 15 & 43 \\
\hline Farm animals & 3 & 1 & 6 & 7 & 17 \\
\hline Total & $9(15 \%)$ & $6(10 \%)$ & $23(38.33 \%)$ & $22(36.67 \%)$ & 60 \\
\hline
\end{tabular}


Fig.1 Bacterial culture in Hektoen enteric plate

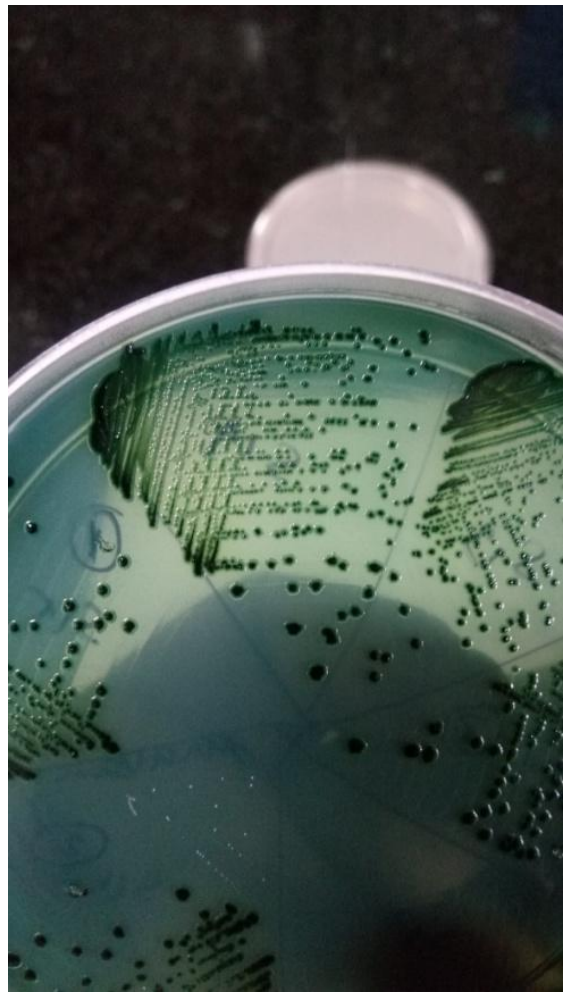

Fig.2 Biochemical test in TSI agar

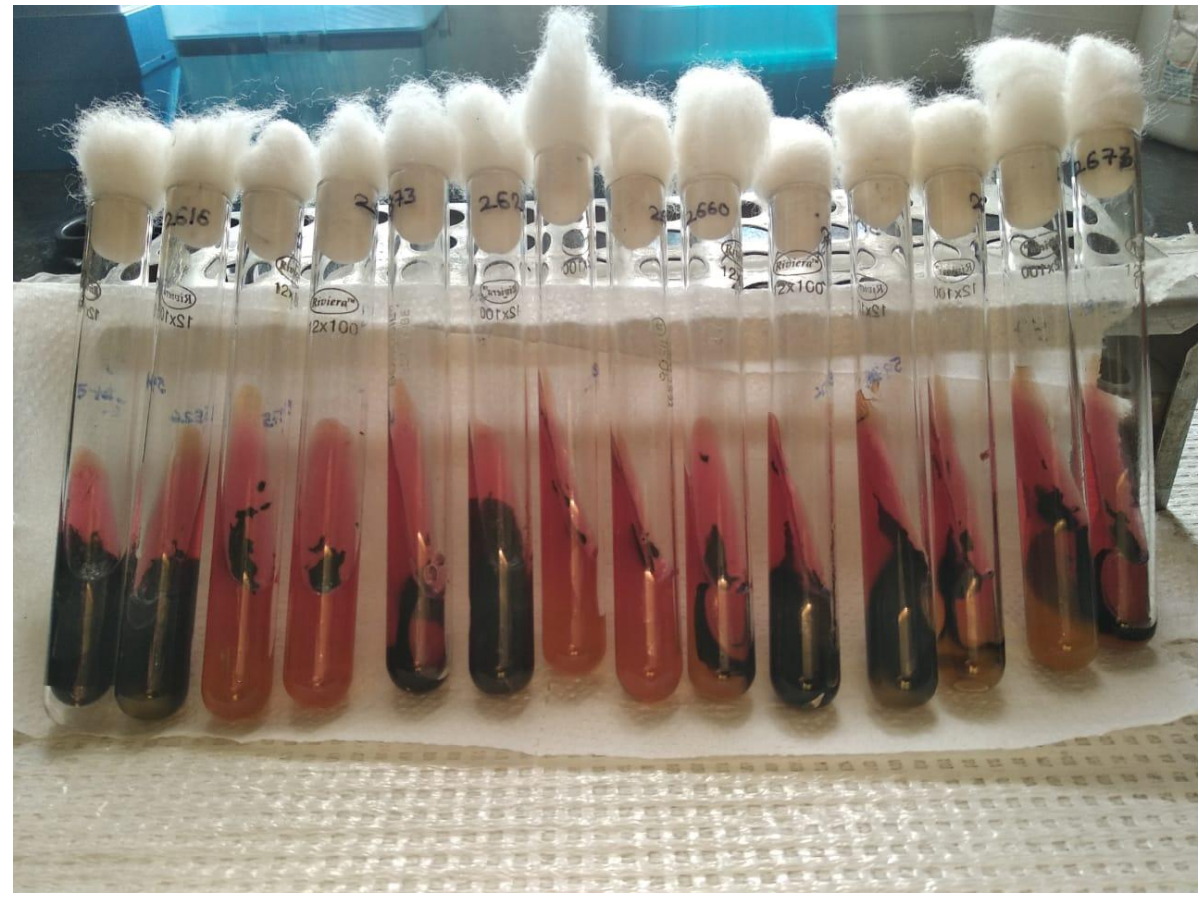


Fig.3 invA gene PCR

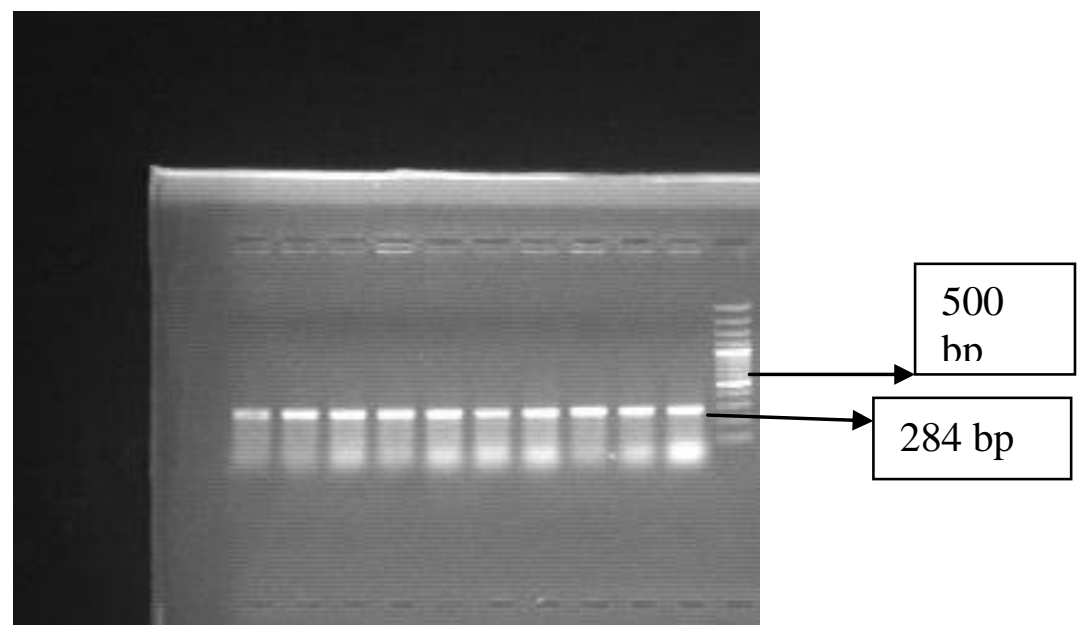

Lanes 1-10: Salmonella isolates

Lane 11: 100 bp ladder

Fig.4 Biofilm assay in 96 welled microtitre plate

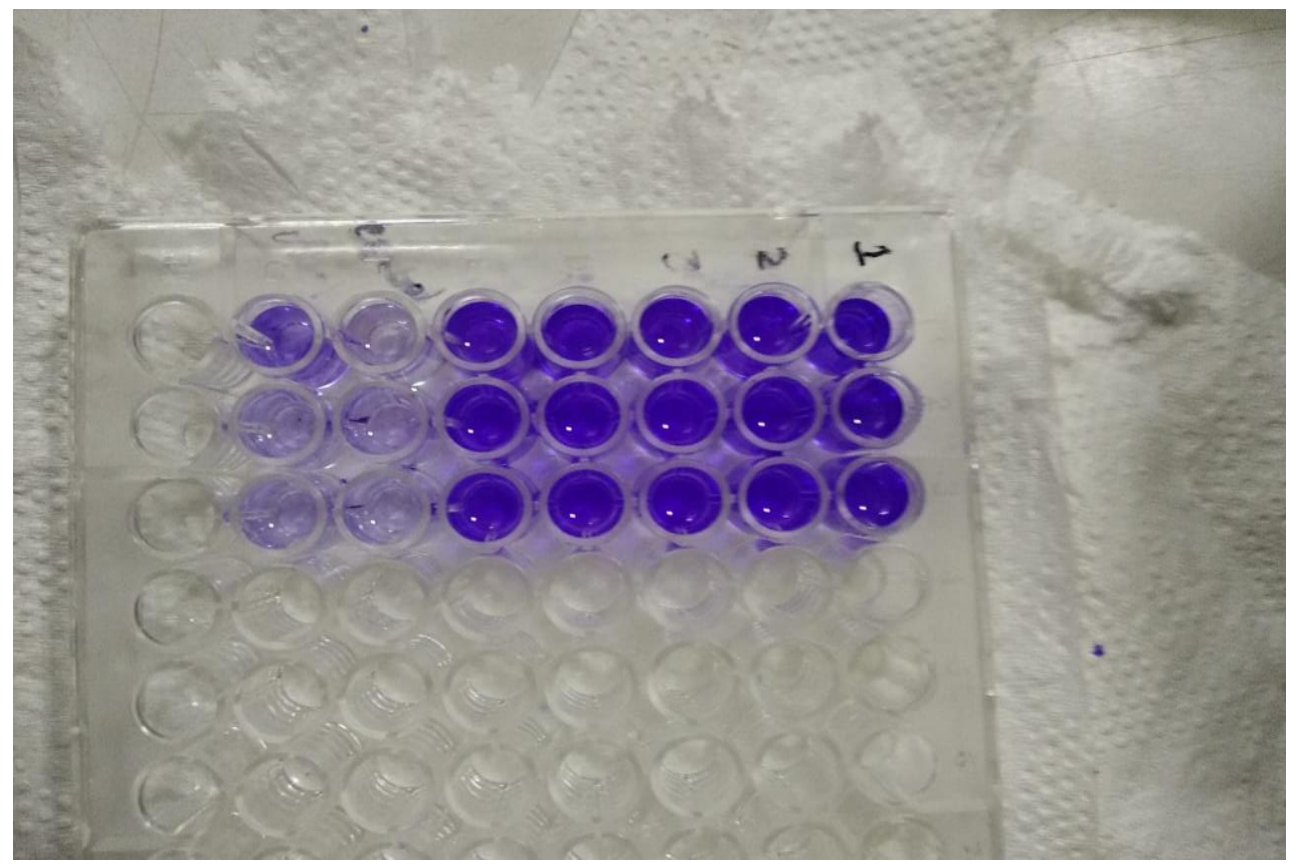

Under in vitro conditions, environmental conditions such as temperature, $\mathrm{pH}$, osmolarity, media composition etc affect biofilm production. It has been proven nutrient less medium favours high quantity of biofilm formation in Salmonella sps., Moreover the serovars have no significant influence on biofilm production (Stepanovic et al., 2004). Therefore, in the current study serovars were not taken into consideration while analyzing the results. It is of more obvious from the current study that around $60 \%$ of the isolates were moderate to strong biofilm producers. This is of high significance 
as biofilms contribute to both virulence and antibiotic resistance of the bacteria. Moreover, biofilms contribute to the survival of bacteria in meat and other food products. Around $40 \%$ of the poultry isolates and $35 \%$ farm animal isolates were moderate biofilm producers followed by $37.5 \%$ and $40 \%$ strong biofilm producers in poultry and farm animal isolates, respectively. Previous reports revealed that around 50\% Salmonella isolates from poultry origin were biofilm producers (Marin et al., 2009). The biofilm formation provides an added advantage of persistence of bacterial species in spite of regular cleaning and disinfection. This possesses risk to food safety and in turn human health. Therefore, the current study is of importance in the public health context.

\section{References}

Galen, J.E., Ginocchio, C. and Costeas, P. 1992. Molecular and functional characterization of the Salmonella invasion gene invA: homology of invA to members of a new protein family. Journal of Bacteriology, 174: 43384349.

Lianou, A. and Koutsoumanis, K.P. 2012. Strain variability of the biofilmforming ability of Salmonella enterica under various environmental conditions. International Journal of Food Microbiology, 160: 171-178

López, D., Vlamakis, H. and Kolter, R. 2010. Biofilms. Cold Spring Harbor Perspectives in Biology 2, a000398.

Majowicz, S.E., Musto, J., Scallan, E., Angulo, F.J., Kirk, M., O’Brien, S.J.,
Jones, T.F., Fazil, A. and Hoekstra, R.M. $2010 . \quad$ International Collaboration on Enteric Disease 'Burden of Illness' Studies. The global burden of nontyphoidal Salmonella gastroenteritis. Clinical Infectious Diseases, 50: 882-889.

Marin, C., Hernandez, A. and Lainez, M. 2009. Biofim development capacity of Salmonella strains isolated in poultry risk factors and their resistance against disinfectants. Poultry Science, 88: 424-431.

Merino, L., Procura, F., Trejo, F.M., Bueno, D.J. and Golowczyc, M.A. 2017. Biofilm formation by Salmonella sp. in the poultry industry: Detection, control and eradication strategies. Food Research International, https://doi.org/10.1016/j.foodres.2017. 11.024 .

Steenackers, H., Hermans, K., Vanderleyden, J. and De Keersmaecker, S.C.J., 2012. Salmonella biofilms: an overview on occurrence, structure, regulation and eradication. Food Research International, 45: 502-531.

Stepanovic, S., Cirkovic, I., Ranin, L. and Svabic-Vlahovic, M. 2004. Biofilm formation by Salmonella spp. And Listeria monocytogenes on plastic surface. Letters in Applied Microbiology 38: 428-432.

WHO. 2013. Integrated Surveillance of Antimicrobial Resistance: Guidance from a WHO Advisory Group. World Health Organization, Geneva, Switzerland.

\section{How to cite this article:}

Sophia Inbaraj, Ravi Kant Agrawal, R.K. Agarwal, Prasad Thomas, Manish Kumar, Abhishek and Pallab Choudhury. 2019. Quantification of Biofilm Formation in Indian Isolates of Salmonella enterica. Int.J.Curr.Microbiol.App.Sci. 8(02): 2219-2223.

doi: https://doi.org/10.20546/ijcmas.2019.802.257 